\title{
Theta frequency stimulation induces a local form of late phase LTP in the CAl region of the hippocampus
}

\author{
Yan-You Huang ${ }^{2}$ and Eric R. Kandel ${ }^{1,2,3,4}$ \\ ${ }^{1}$ Kavli Institute for Brain Science, ${ }^{2}$ Center for Neurobiology and Behavior, College of Physicians and Surgeons of Columbia \\ University, New York State Psychiatric Institute, and ${ }^{3}$ Howard Hughes Medical Institute, Columbia University, New York, \\ New York 10032, USA
}

The late phase of LTP (L-LTP) is typically induced by repeated high-frequency stimulation. This form of LTP requires activation of transcription and translation and results in the cell-wide distribution of gene products that can be captured by other marked synapses. Here we report that theta frequency stimulation $(5 \mathrm{~Hz}, 30 \mathrm{sec})$ applied to the Schaeffer-collateral pathway can induce a form of late phase of LTP that is restricted locally to the dendritic compartment. The late phase of theta frequency LTP is maintained even in isolated CAl dendrites and is dependant on dendritic translation and actin cytoskeletal regulation, but is independent of transcription. This local form of L-LTP is not accessible to synaptic capture by other synapses, indicating that this form of LTP is restricted to the synaptic compartment. These results indicate that different patterns of synaptic stimulation can induce distinct forms of LTP that may have different roles in memory storage.

Hippocampal long-term synaptic potentiation (LTP) has a number of properties that make it an attractive model for memory storage. LTP can be divided into at least two distinct temporal phases, i.e., early phase LTP (E-LTP) and late phase LTP (L-LTP). ELTP is typically induced by a single train of high-frequency stimulation and is dependent on the modification of pre-existing protein. In contrast, L-LTP is typically induced by multiple trains of stimulation at $100 \mathrm{~Hz}$ or bursts of stimulation at $100 \mathrm{~Hz}$ repeated at $5 \mathrm{~Hz}$ (theta bursts). These forms of L-LTP are blocked by both inhibitors of translation and transcription (Frey et al. 1996; Nguyen and Kandel 1997; Nayak et al. 1998; Barco et al. 2002; Kelleher III et al. 2004). New proteins required for the stabilization of these forms of L-LTP are thought to be synthesized in the cell body and delivered to the activated synapse. The cell body is therefore critical for the maintenance of these forms of L-LTP (Frey et al. 1989; Frey and Morris 1997; Dudek and Fields 2002; Woo and Nguyen 2003). However, recent evidence indicates that mRNA can also be translated locally in dendrites of pyramidal neurons (Martin et al. 2000; Steward and Schuman 2001; Jiang and Schuman 2002). Kang and Schuman (1996) have reported that a form of LTP induced by bath application of BDNF to hippocampal slice is restricted to the local dendrites and does not require protein synthesis in the cell body. In this form of LTP, both the early and late phases are blocked by translation inhibitors anisomycin or ramamycin (Kang and Shuman 1996; Tang et al. 2002). This is different from the blockade produced by these inhibitors in L-LTP induced by repeated high-frequency stimulation (Impey et al. 1998; Nayak et al.1998; Tang et al. 2002; Alarcon et al. 2004; Kelleher III et al. 2004), indicating that chemically induced local LTP may not be the same as the L-LTP induced by electrical stimulation. However, bath application of BDNF affects all of the synapses in the slice, and as a result, it is not known whether this form of LTP is input specific. The involvement of local protein synthesis in L-LTP is also supported by the

\footnotetext{
${ }^{4}$ Corresponding author.

E-mail ERK5@columbia.edu; fax (212) 543-5474.

Article published online ahead of print. Article and publication date are at http://www.learnmem.org/cgi/doi/10.1101/lm.98905.
}

"synaptic capture" experiment. In Aplysia and hippocampal slices, rapamycin-sensitive local protein synthesis is required for the stabilization of synapse-specific synaptic facilitation in the synaptic capture paradigm (Frey and Morris 1997; Martin et al. 1997, 2000; Casadio et al. 1999; Barco et al. 2002). However, in synaptic capture, local protein synthesis is not sufficient by itself to induce LTP or LTF. It requires the interaction between gene products produced by a strong stimulation in other pathways and the products of local translation activated by the marking stimulus. These findings raise the following question: Can the L-LTP restricted in local synapse be induced by an electrical stimulation applied to a single input pathway?

To address this question, we have studied a form of longlasting synaptic potentiation in the CA1 region of hippocampus recently found to be elicited following a brief duration of theta frequency stimulation (5 Hz, $30 \mathrm{sec}$ ) (Thomas et al. 1996, 1998; Winder et al. 1999; Geoffrey et al. 2002; Morozov et al. 2003). This form of LTP is stable for up to $3 \mathrm{~h}$ (Morozov et al. 2003). Although some properties of the early phase of this form of LTP have been studied (Thomas et al. 1996, 1998; Winder et al. 1999; Morozov et al. 2003), little is known about the properties of the late phase. Here we report that theta frequency stimulation $(5 \mathrm{~Hz}$, $30 \mathrm{sec}$ ) induces a late phase of LTP that is independent of transcription. It specifically requires local protein synthesis and the late phase is unimpaired even when the dendrite of hippocampal pyramidal neuron is dissociated from the cell body. In contrast to L-LTP induced by high-frequency stimulation, theta LTP in one pathway cannot be "captured" by marking a second synaptic pathway. These results indicate that different patterns of electrical stimulation may induce different forms of late-phase LTP. The L-LTP induced by repeated high-frequency tetanus appears to distribute gene products to all synapses of the neuron so that they can be captured by a marking stimulus at other synapses. In contrast, the late phase of LTP induced by theta frequency stimulation $(5 \mathrm{~Hz}, 30 \mathrm{Sec})$ activates only the signaling pathway of a local synaptic compartment. This form of L-LTP is restricted to the activated synapse and cannot be captured by stimulation that marks other synapses. These two forms of L-LTP may have different roles in the processing of information by neurons related to memory storage. 


\section{Results}

The late phase of LTP induced by theta frequency stimulation requires translation but not transcription

We first asked whether LTP induced by theta frequency stimulation lasts for a long period of time. Here, we show that $5-\mathrm{Hz}$ (30 Sec) stimulation induced a synaptic potentiation that lasted up to $5 \mathrm{~h}$ without significant decay (Fig. 1A). The average slope of the fEPSPs at 3 and $5 \mathrm{~h}$ after the $5-\mathrm{Hz}$ stimulation were not significantly different from the EPSPs $1 \mathrm{~h}$ after $5-\mathrm{Hz}$ stimulation ( 1 h: $146 \pm 9 \%, 3$ h: $151 \pm 11 \%, 5$ h: $149 \pm 14 \%, n=6$, $t$-test, $P>0.5)$.

We next examined the effect of a protein synthesis inhibitor on this form of LTP. Emetine $(100 \mu \mathrm{M})$ was added into the bath $60 \mathrm{~min}$ before the $5-\mathrm{Hz}$ stimulation. Emetine treatment significantly reduced the late phase of theta LTP. The LTP in emetine treated slices was $108 \pm 10 \%(n=7) 3 \mathrm{~h}$ after the $5-\mathrm{Hz}$ stimulation, which was significantly different from the LTP in control experiments $(151 \pm 11 \%, n=6, t$-test, $P<0.01$; Fig. $1 \mathrm{~B})$. We next asked the question: Does this form of L-LTP require transcription? We found that actinomycin D $(40 \mu \mathrm{M})$ had no effect on the maintenance of late-phase theta LTP. There was no significant difference between the LTP in the control experiment (in $0.1 \%$ DMSO) and the LTP in the presence of Actinomycin D $3 \mathrm{~h}$ after 5-Hz stimulation (Control: $146 \pm 11 \%, n=6$; Actinomycin D:
$158 \pm 16 \%, n=7, P>0.5$; Fig. 1 C). In contrast to LTP induced by $5-\mathrm{Hz}$ stimulation, LTP induced by repeated high-frequency stimulation $(4 \times 100 \mathrm{~Hz})$ was significantly reduced in the presence of Actinomycin D ( Control: $193 \pm 18 \%, n=6$; Actinomycin D: $122 \pm 4 \%, n=6,3 \mathrm{~h}$ after tetanus, $t$-test, $P<0.01$; Fig. $1 \mathrm{D})$. These data indicate that LTP induced by theta frequency stimulation is dependent on translation, but independent of transcription.

The cell body is not required for LTP induced by theta frequency stimulation

We next asked: Is somatic protein synthesis required for LTP induced by theta frequency stimulation? Using microdissection, cell bodies of pyramidal neurons were severed from their apical dendrites in stratum radiatum and fEPSPs were recorded from isolated dendrites (Fig. 2A) (Frey et al. 1989; Woo and Nguyen 2003; Cracco et al. 2005). We found that $5-\mathrm{Hz}$ (30 sec) stimulation still induced a substantial synaptic potentiation in isolated dendrites lasting up to $3 \mathrm{~h}$. There was no significant difference between the LTP produced in isolated dendrites and the LTP produced in control slices (Isolated dendrites: $160 \pm 19 \%, n=8$; Control slices: $152 \pm 16 \%, n=7,3 \mathrm{~h}$ after $5-\mathrm{Hz}$ stimulation, $P>0.5$; Fig. 2B). In contrast to LTP induced by $5-\mathrm{Hz}$ stimulation, L-LTP induced by repeated high-frequency stimulation $(4 \times 100$ $\mathrm{Hz}, 1 \mathrm{~S})$ was significantly impaired in isolated dendrites. Three
A

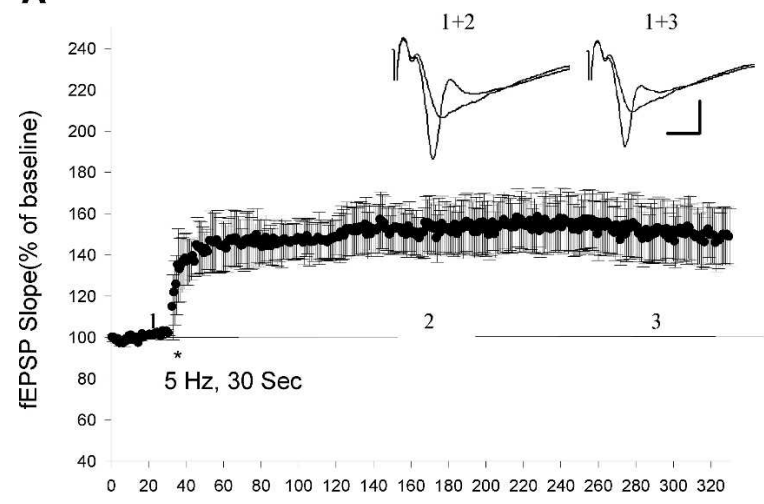

Time (min)

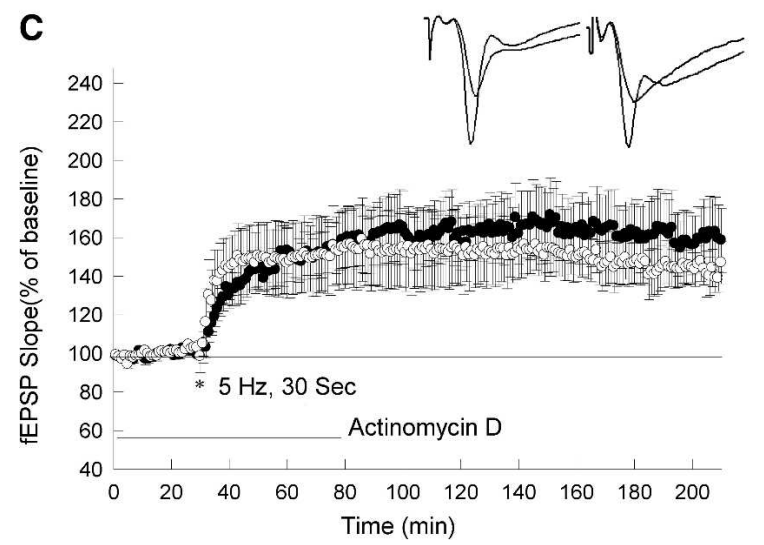

B
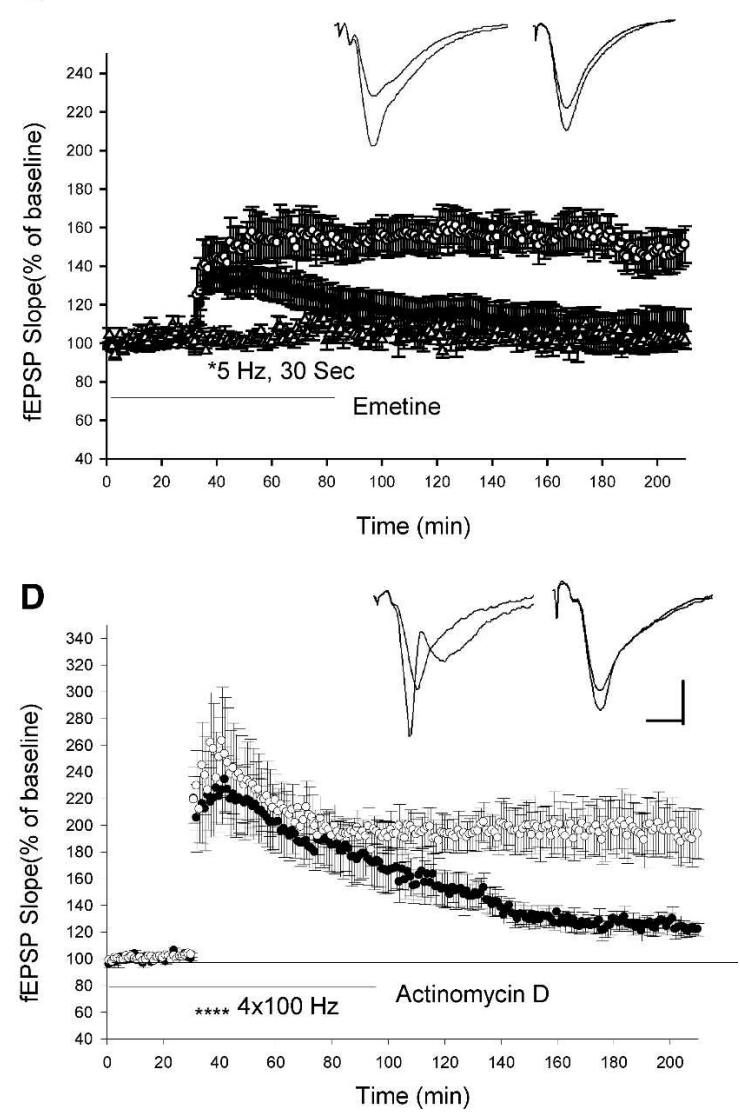

Figure 1. LTP induced by theta frequency stimulation is dependent on translation and independent of transcription. ( $A$ ) LTP induced by theta frequency stimulation is long lasting. Sample traces 10 min before and 3 and $4 \mathrm{~h}$ after theta frequency stimulation are shown in the insets. Calibrations: $3 \mathrm{mV}, 4 \mathrm{msec}$. (B) Application of protein synthesis inhibitor emetine (100 $\mu \mathrm{M})$ blocked the late phase of LTP induced by theta frequency stimulation. $(\circ)$ Control; $(\bullet)$ emetine. The addition of emetine did not alter the baseline EPSPs $(\triangle, n=5)$. (C) Application of transcriptional inhibitor Actinomycin $D$ $(40 \mu \mathrm{M})$ did not block the late phase of LTP induced by theta frequency stimulation. (O) control; ( $\bullet$ ) Actinomycin D. (D) Application of actinomycin D significantly blocked the late phase of LTP induced by four trains of 100-Hz stimulation (3-min apart). (O) Control; ( $\bullet$ ) Actinomycin D. Sample traces in the insets on $B, C, D$ were taken $10 \mathrm{~min}$ before and $180 \mathrm{~min}$ after LTP-inducing stimulation. Calibrations: $2 \mathrm{mV}, 4 \mathrm{msec}$. 
hours after tetanus, LTP in isolated dendrites' slices was $123 \pm 13 \%(n=6)$, which was significantly different from the LTP in the control experiment (206 $\pm 9 \%, n=6, P<0.01$; Fig. 2C). The
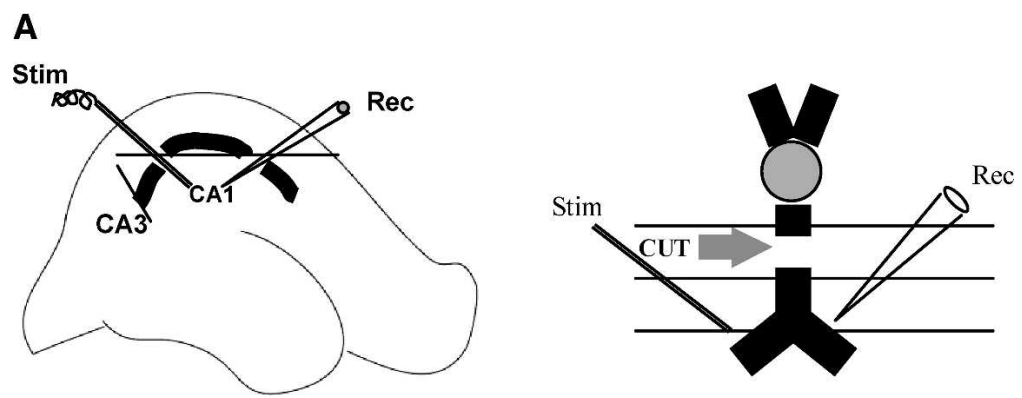

B

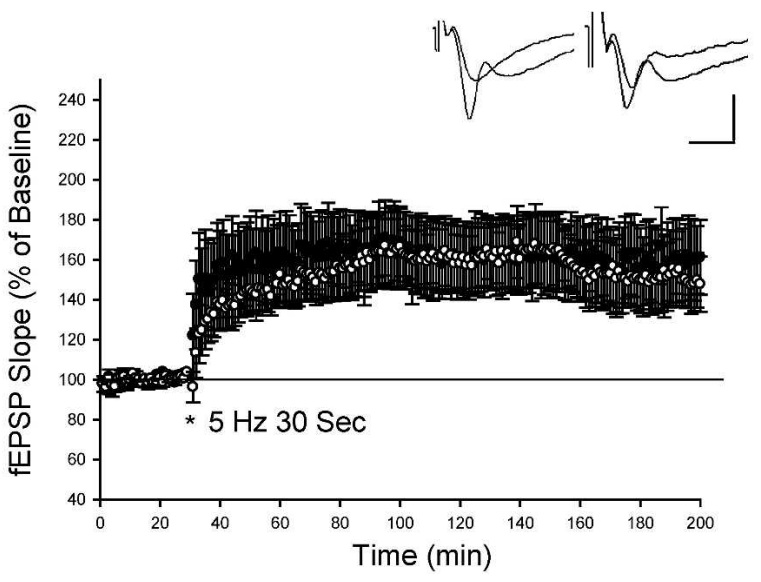

C

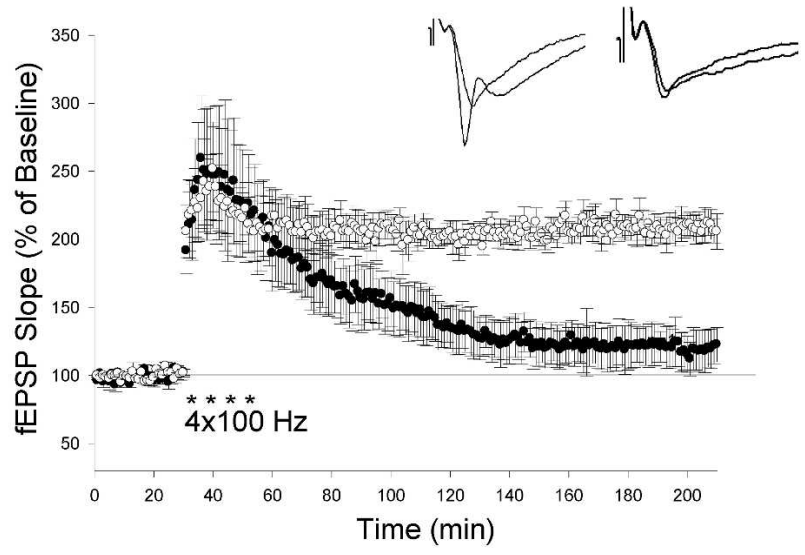

D

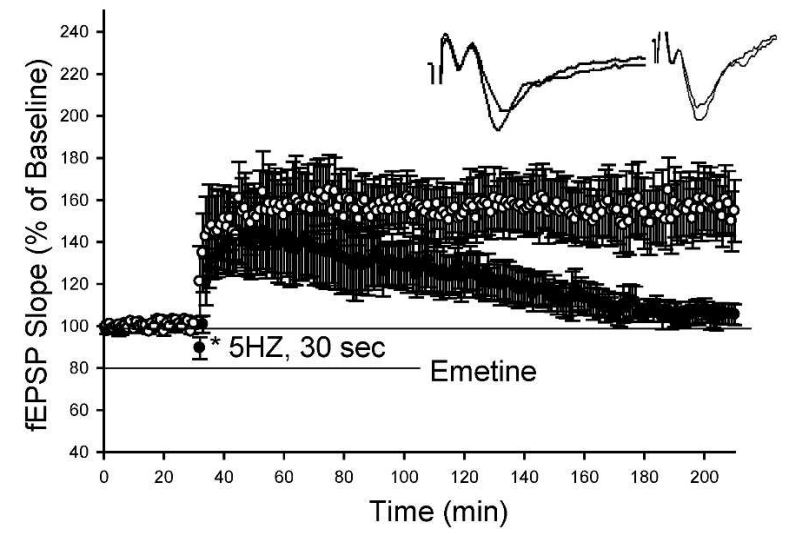

decay of L-LTP induced by repeated tetanus in isolated dendrites indicates that cell bodies of pyramidal neuron were at least partly disconnected from dendrites in the CA1 region.

Early studies of the LTP induced by theta frequency stimulation observed that a negative-going complex spike superimposed on the field EPSP during theta stimulation was associated with the induction of LTP (Thomas et al. 1998). We find that complex spikes still exist in isolated dendrites during the theta stimulation, but that the total number and the amplitude of the spikes were reduced (data not shown). These remaining complex spikes are thought to be initiated in the dendrites (Spruston et al. 1995; Golding et al. 2002; Mehta 2004). The fact that L-LTP was unimpaired, despite the reduction of complex spikes, suggests that complex spikes can be dissociated from the maintenance of LTP under certain conditions. Indeed, a dissociation between complex spikes and theta LTP has been previously observed on the effect of NMDA receptor antagonist APV (Thomas et al. 1998).

We next asked: Is protein synthesis required for the maintenance of theta LTP specifically located in dendrites? To address this question, we examined the effect of protein synthesis inhibition on theta LTP in isolated dendrites. Although theta LTP is normal in isolated dendrites, it was significantly depressed in the presence of the protein synthesis inhibitor emetine $(100 \mu \mathrm{M})$ (Isolated dendrites: $155 \pm 15 \%, n=6$; Isolated dendrites in emetine: $105 \pm 5 \%, n=6,3 \mathrm{~h}$ after $5-\mathrm{Hz}$ stimulation, $P<0.05$; Fig. 2D). This result indicates that dendritic translation is required for the maintenance of late-phase LTP induced by theta frequency stimulation.

The rapamycin-signaling pathway and intact regulation of actin cytoskeleton are required for LTP induced by theta frequency stimulation

The rapamycin-dependent pathway is a key signaltransduction pathway for dendritic mRNA translation (Jiang and Schuman 2002; Tang et al. 2002) . Both the L-LTP induced by repeated high-frequency stimulation and L-LTP induced by BDNF application can be blocked by inhibitor of mTOR, rapamycin (Barco et al. 2002; Tang et al. 2002; Alarcon et al. 2004). We next examined the effect of rapamycin on LTP induced by theta frequency stimulation. In the presence of rapamycin $(0.5 \mu \mathrm{M})$, theta frequency stimulation $(30 \mathrm{sec})$ still induced the early phase of LTP. However, the late phase of LTP was significantly decreased (Control: $151 \pm 10 \%, n=7$; rapamycin:

Figure 2. LTP induced by theta frequency stimulation is unimpaired in isolated dendrites. (A) Schematic diagram showing the two incisions made to isolate CA1 dendrites and showing the placement of recording (Rec) and stimulating electrodes (Stim). (B) LTP induced by theta frequency stimulation in isolated dendrites is unimpaired. (O) LTP in the intact slices; ( $\bullet$ LTP in the isolated dendrites. (C) LTP induced by four trains of $100-\mathrm{Hz}$ stimulation is reduced in isolated dendrites. (O) L-LTP in intact slices; $(\bullet)$ L-LTP in isolated dendrites. (D) Application of emetine $(100 \mu \mathrm{M})$ blocked late phase of theta LTP in isolated dendrites. (O) Control; $(\bullet)$ emertine-treated slices. Sample traces before and $3 \mathrm{~h}$ after LTP are shown in the insets. Calibration: $2 \mathrm{mV}, 10 \mathrm{~ms}$. 
$114 \pm 6 \%, n=7,3 \mathrm{~h}$ after $5-\mathrm{Hz}$ stimulation, $P<0.05$; Fig. $3 \mathrm{~A}$ ). The effect of this blockade is different from that in BDNF-induced L-LTP, in which rapamycin blocks both the early and late phase of LTP (Tang et al. 2002).

Cytoskeletal protein present in dendtritic spines are thought to play an important role in microstructural changes induced by synaptic plasticity (Geinisman et al. 1996; Engert and Bonhoeffer 1999; Trachtenberg et al. 2002). LTP induced by repeated highfrequency stimulation is blocked by inhibitors of actin polymer-


Figure 3. The rapamycin-signaling pathway and intact regulation of actin cytoskeleton are required for LTP induced by theta frequency stimulation. (A) Application of rapamycin selectively blocked the late phase of theta LTP. (O) Control; $(\bullet)$ Rapamycin. The addition of rapamycin did not alter baseline EPSPs $(\triangle, n=5)$. (B) Application of Latruncullin A blocked theta LTP. ( $($ ) control; $(\bullet)$ Latrucullin. The addition of Latrucullin did not alter baseline EPSPs $(\triangle, n=5)$. (C) Application of NMDA antagonist DL-APV inhibited theta LTP. (O) control; $(\bullet)$ DL-APV. Sample traces before and $3 \mathrm{~h}$ after LTP are shown in the insets. Calibration: $4 \mathrm{mV}, 5 \mathrm{msec}$. ization (Krucker et al. 2000; Fukazawa et al. 2003). To determine the effect of inhibition of actin polymerization on theta LTP, we examined theta LTP in the presence of actin filimental inhibitor Latrunculin A $(0.1 \mu \mathrm{M})$. Latrunculin A treatment severely impaired LTP induced by $5-\mathrm{Hz}(30 \mathrm{sec})$ stimulation. LTP was $100 \pm 2 \%(n=7)$ in the Latrunculin A-treated slices $3 \mathrm{~h}$ after $5-\mathrm{Hz}$ stimulation, which is significantly different from the LTP in the control experiments ( $158 \pm 15 \%, n=6, P<0.01$; Fig. $3 \mathrm{~B})$.

Previous studies reported that the early phase of theta LTP is partly independent of the NMDA receptor (Morozov et al. 2003). Does the late phase of theta LTP depend on the activation of NMDA receptor? Here, we show that LTP induced by $5-\mathrm{Hz}(30$ sec) stimulation is significantly depressed in the presence on NMDA inhibitor DL-APV $(100 \mu \mathrm{M})$, indicating that the late phase of theta LTP is dependent on NMDA receptor activation (Control: $155 \pm 15 \%, n=6$; APV: $114 \pm 8 \%, n=7, P<0.05$; Fig. 3C).

Theta frequency-induced LTP is not accessible to "synaptic capture"

In transcription-dependent L-LTP, the long-term process induced by repeated trains of high frequency in one pathway can be "captured" in a second pathway receiving only a single train of tetanus, a stimulation that would normally produce only E-LTP. (Frey and Morris 1997; Martin et al. 2000; Barco et al. 2002; Martin and Kosik 2002; Alarcon et al. 2004). We next asked: Is LTP induced by theta frequency stimulation accessible to "synaptic capture"? We first replicated the "capture" experiment reported previously (Frey and Morris 1997; Barco et al. 2002; Alarcon et al. 2004). Repeated high-frequency stimulation $(4 \times 100$ $\mathrm{Hz}$ ) was applied to pathway 1 (S1) to induce L-LTP (Fig. 4B, top). A single train of tetanus $(1 \times 100 \mathrm{~Hz})$ was then applied to the second pathway (S2) 60 min after $4 \times 100-\mathrm{Hz}$ stimulation in the S1 pathway. This single tetanus, which normally induces a transient LTP, now induced a longer lasting LTP $(163 \pm 19 \%, n=6$, at $90 \mathrm{~min}$, Fig. 4B, bottom). We next examined the effect of $5-\mathrm{Hz}$ stimulation. The $5-\mathrm{Hz}(30 \mathrm{sec})$ stimulation induced synaptic potentiation is input specific. The LTP induced by $5-\mathrm{Hz}$ stimulation in one pathway (S1) did not affect the baseline EPSPs in the second pathway (S2, Fig. 4C). To test the effect of "synaptic capture", a single train of tetanus $(1 \times 100 \mathrm{~Hz})$ was applied to the second pathway (S2) 60 min after 5-Hz stimulation in S1 pathway. We found that this single train of tetanus only induced a short-lasting LTP $(108 \pm 7 \%, n=7$ at $90 \mathrm{~min})$ (Fig. 4C, bottom) that was significantly different from the LTP induced in the second pathway of $4 \times 100-\mathrm{Hz}$ stimulation (Fig. $4 \mathrm{~B}$, bottom, $P<0.05)$. To test whether the effective capture of theta LTP requires a shorter time window between stimuli, we also applied $1 \times 100-\mathrm{Hz}$ stimulation (S2) $15 \mathrm{~min}$ after the 5 - $\mathrm{Hz}$ stimulation in S1. Application of a single tetanus in this reduced time window still failed to obtain an enduring form of LTP in the S2 pathway (109 $\pm 10 \%$, at $90 \mathrm{~min}, n=7, P<0.05$ ) (Fig. $4 \mathrm{D}$, bottom). These data are consistent with the results of the transcription inhibitor and support the idea that the LTP induced by the theta frequency stimulation is restricted to local synapses and does not require transportation of gene product from cell bodies to synapses in this form of LTP.

The relationship of theta frequency stimulation-induced LTP to other forms of L-LTP

The results above indicate that L-LTP induced by theta frequency stimulation is different from L-LTP induced by high-frequency tetani, in that it does not require transcription and somatic protein synthesis. This raised the question: What is the relationship of this form of LTP to the LTP induced by repeated highfrequency stimulation? To address this issue, we tested whether the two forms of L-LTP occlude each other. We first induced 
A


Figure 4. LTP induced by theta frequency stimulation is not accessible to synaptic capture. (A) Diagram illustrating the placement of stimulating (S1, S2) and recording electrodes (R) for synaptic capture experiments. (B) Four trains of $100 \mathrm{~Hz}$ tetanus delivered to the S1 pathway induced L-LTP (top). A single train of $100-\mathrm{Hz}$ tetanus applied $60 \mathrm{~min}$ after in S2 pathway induced an enduring LTP (bottom). (C) Theta frequency stimulation (5 Hz, 30 sec) delivered to S1 induced LTP in this pathway (top). A single train of 100-Hz stimulation applied 60 min after in S2 failed to induce enduring LTP (bottom). (D) A single train of tetanus $(1 \times 100 \mathrm{~Hz})(\mathrm{S} 2)$ applied 15 min after 5- $\mathrm{Hz} \mathrm{LTP}$ in S1 induces a transient LTP (bottom). Insets in B, C, and D are the sample traces before and $90 \mathrm{~min}$ after the LTP-inducing protocol. Calibration: $3 \mathrm{mV}, 5 \mathrm{msec}$.

theta LTP by $5-\mathrm{Hz}(30 \mathrm{sec})$ stimulation. Forty minutes after theta LTP, we applied $4 \times 100-\mathrm{Hz}(1 \mathrm{~S})$ tetanic stimulation. The LTP induced by repeated high-frequency stimulation was significantly depressed (occluded) after theta LTP $(122 \pm 19 \%, n=7)$, compared with the LTP without priming of $5-\mathrm{Hz}$ stimulation in control experiments ( $204 \pm 16 \%, n=7$, at $3 \mathrm{~h}, P<0.05$; Fig. $5 \mathrm{~A})$. In contrast, when $5 \mathrm{~Hz}$ stimulation was applied after LTP induced by $4 \times 100-\mathrm{Hz}$ tetanus, this stimulation still elicited a longlasting synaptic potentiation. Although there was a clear reduction of the early component, the late phase of LTP induced by $5-\mathrm{Hz}$ stimulation was not significantly different from that in control experiments (Control: $146 \pm 12 \%, n=6$; Priming: $131 \pm 20 \%, n=6 ; P>0.5$, Fig. 5B). These experiments indicate that LTP induced by theta frequency stimulation shares some, but not all, of the component of LTP induced by repeated tetanization.

We next examined the relationship of theta LTP with BDNFinduced LTP, a form of LTP reported to be restricted in dendrites (Kang and Shuman 1996). We found that a brief application of BDNF (50 ng/mL) induced a moderate and long-lasting LTP. Seventy minutes after induction, when the BDNF-induced LTP reached a stable level of $130 \%, 5-\mathrm{Hz}(30 \mathrm{sec})$ stimulation was applied. As shown in Figure 5C, BDNF-induced synaptic potentiation significantly occluded the late component of theta LTP (BDNF-treated slices: $107 \pm 5 \%, n=8$; control slices: $145 \pm 7 \%$, $n=7,80 \mathrm{~min}$ after the $5-\mathrm{Hz}$ stimulation, $P<0.01$; Fig. $5 \mathrm{C}$ ). This result indicates that these two forms of LTP may share some common feature.

\section{Discussion}

It has long been thought that new proteins required for the maintenance of late-phase LTP are synthesized in the cell body. With the discovery of synaptic capture of L-LTP, it became clear that some of the requirement for the protein synthesis is achieved locally in dendritic spines (Martin et al. 2000; Jiang and Shuman 2002; Martin and Kosik 2002). Similarly, the LTP induced by BDNF in isolated dendrites is also mediated by local dendritic translation (Kang and Shuman 1996). However, both of these studies have some limitations. In the case of "synaptic capture," it is not clear whether local protein synthesis is by itself sufficient for maintenance of the late phase of LTP, or whether it is an ancillary mechanism that also requires the transport of newly synthesized protein from the cell body. In BDNF-induced LTP, the BDNF was applied in the bath medium, thereby affecting all synapses in the slice (Kang and Shuman 1996). It is therefore not known whether the L-LTP so induced is input specific. It is also not known whether this form of L-LTP allows synaptic capture. The L-LTP we describe here, induced by theta frequency stimulation, is local, according to several criteria. First, this form of LTP is independent of transcription, but is dependent on a rapamycin-sensitive pathway. Second, the theta LTP is intact after the soma of the pyramidal neurons are disconnected from the dendrites. Third, protein synthesis inhibitor blocked theta LTP induced in isolated dendrites. Finally, this form of L-LTP does not produce synaptic capture, indicating that this form of L-LTP does 
A

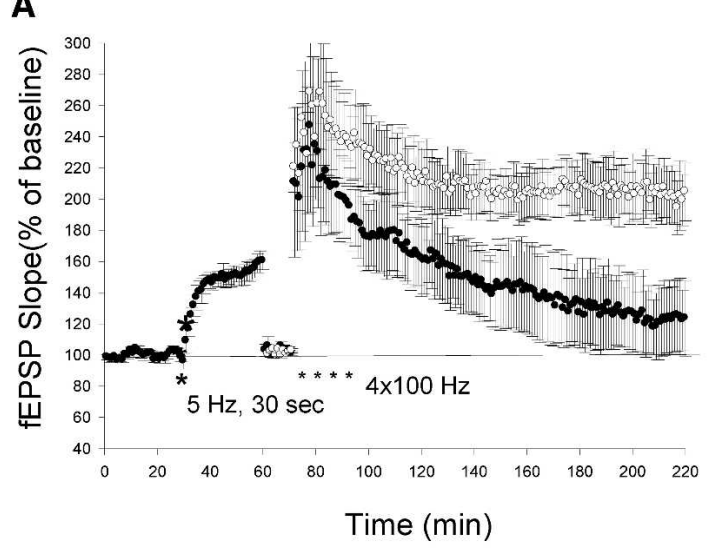

B

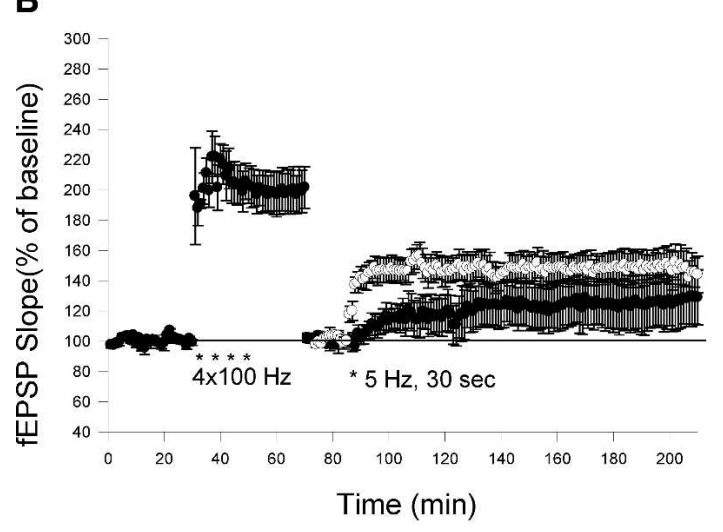

C

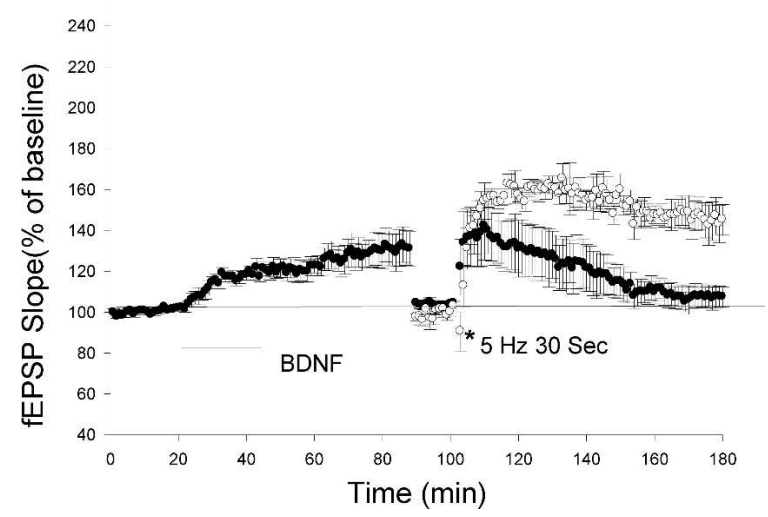

Figure 5. The relationship of LTP induced by theta frequency stimulation and other forms of LTP. (A) Theta LTP occludes L-LTP induced by four trains of $100-\mathrm{Hz}$ stimulation. Thirty minutes after theta LTP, the stimulus intensity was reduced to reach baseline level before $5-\mathrm{Hz}$ stimulation and four trains of $100-\mathrm{Hz}$ stimulation (1 sec) were applied. (O) Four train induced L-LTP without priming of theta frequency stimulation; $(\bullet)$ four train-induced LTP after the induction of theta LTP. ( $B$ ) LTP induced by four trains of tetanus did not significantly occlude the late phase of theta LTP. (O) Theta LTP without priming of four trains LTP; $(\bullet)$ theta LTP after the induction of four trains LTP. (C) BDNF-induced LTP occludes the late phase of theta LTP. ( $\odot)$ Theta LTP in control experiments; $(\bullet)$ theta LTP after the BDNF-induced potentation.

not give rise to a cell-wide distribution of proteins. Thus, there are at least two different forms of late-phase LTP induced by different patterns of synaptic activation. One form of L-LTP is induced by repeated high-frequency stimulation (strong stimu- lation), this L-LTP depends on transcription and is associated with a cell-wide distribution of protein products. This "strong" stimulation appears to send a signal from the synapse to the nucleus to activate transcription as well as translation in the cell body. The newly synthesized proteins are then transported to all of the synapses of the neuron. The second form of L-LTP that we describe here is induced by a low-frequency stimulation $(5 \mathrm{~Hz}, 30$ sec). This form of LTP is independent of transcription and does not induce a cell-wide distribution of gene products, but is dependent on translation in the local dendrite compartment only. Thus, the induction of different forms of synaptic potentiation is dependent on the nature and precise pattern of stimulation.

The occlusion experiments suggest that theta L-LTP and the high-frequency L-LTP may share a common mechanism. Both of these forms of late phase are dependent on the activation of NMDA receptors. Since high-frequency stimulation activates somatic protein synthesis as well as dendritic translation (Tang et al. 2002), these two forms of L-LTP may overlap in the activation of local rapamycin-dependent signaling pathway. On the other hand, the occlusion of theta L-LTP by BDNF-induced LTP does not mean these two types of L-LTP share exactly the same mechanism; they may only share the downstream signaling pathway, since rapamycin and protein synthesis inhibitors have different effects on the early phase of these two forms of LTP (Kang and Shuman 1996; Tang et al. 2002).

The finding of "synaptic capture" revealed a principle of "sharing" synaptic potentiation. Enduring LTP in one synaptic pathway could be captured in the second pathway of the same neuron by a mark stimulation in a limited time window (Frey and Morris 1997; Martin et al. 1997, 2000; Martin and Kosik 2002; Fonseca et al. 2004). Our findings indicate, however, that not all enduring forms of LTP are accessible to synaptic capture. Instead, certain patterns of synaptic activity can produce an increase in synaptic weight that is enduring, but may never be captured. This local form of L-LTP reveals an additional model for synapse-specific L-LTP. Different from the L-LTP induced by repeated high-frequency stimulation, this model allows synapsespecific L-LTP to be achieved by a modest stimulation that does not send signals to the nucleus. It lowers the threshold required for synapse-specific and protein synthesis-dependent L-LTP and thus greatly increases the capacity of information processing in the brain.

\section{Materials and Methods}

Transverse slices $(400 \mu \mathrm{m})$ of acutely dissected mouse hippocampus were prepared from C57/B6 mice aged 7-10 wk. Slices were maintained at $28^{\circ} \mathrm{C}$ in an interface chamber with continuous perfusion of ACSF (in millimolars: $124 \mathrm{NaCl}, 1.2 \mathrm{MgSO}_{4}, 4 \mathrm{KCl}$, $1.0 \mathrm{NaH}_{2} \mathrm{PO}_{4}, 2.0 \mathrm{CaCL}_{2}, 26 \mathrm{NaHCO}_{3}$, and 10 D-glucose) at 2 $\mathrm{mL} / \mathrm{min}$, bubbled with $95 \% \mathrm{O}_{2}$ and $5 \% \mathrm{CO}_{2}$. Experiments were started at least $2 \mathrm{~h}$ after the slice dissection. Field EPSPs were recorded in the stratum radiatum of the CA1 region by using ACSF-filled glass electrodes (1-3 M $\Omega$ ). Stimuli were delivered to Schaffer collateral afferents through bipolar stainless-steel electrodes $(25 \mu \mathrm{M}$ wire diameter, FHC). Stimulation intensity $(0.05$ msec duration) was adjusted to evoke fEPSP amplitudes that were $30 \%-40 \%$ of maximal size, and baseline responses were elicited one per minute. In some experiments, two pathway recordings were used. Two stimulating electrodes were placed on either side of the recording electrode in stratum radiatum (Fig. 4A) and stimuli were delivered 10 -sec apart. The two afferent pathways were considered independent if there was no paired-pulse facilitation when two stimuli were coupled in a 50-msec interval. LTP was elicited by either $5-\mathrm{Hz}(30 \mathrm{sec})$ or $1-4$ trains of $100-\mathrm{Hz}(1 \mathrm{sec})$ stimulation with the same intensity and pulse duration used in sampling of baseline EPSPs.

In some experiments, the cell bodies of pyramidal neurons were severed from their apical dendrites in the stratum radiatum.

\section{Learning \& Memory}

www.learnmem.org 
Two incisions were made on the slices under a dissecting microscope. One cut was made just below the pyramidal cell body layer of CA1 region. Another cut was made between the CA3 and CA1 region (Fig. 2A). The cut slices were allowed to recover for about $2 \mathrm{~h}$ before fEPSPs recording. The isolation of dendrites was verified electrophysiologically by failure to elicit population spikes in the cell body layer by stimulating the Shaffer Collateral pathway (Kang and Schuman 1996; Woo and Nguyen 2003; Gracco et al. 2005).

For bath application, the following drugs were made and stored as concentrated stock solution and then diluted 1000-fold when applied to the perfusion solution as follows: emetine (dissolved in DMSO, Sigma); DL-APV (D-(-)-2-amino-5-phosphonopentanotic acid, Sigma); actinomycin D (Sigma, dissolved in DMSO); rapamycin (Calbiochem, in DMSO); latrunculin A (Molecular Probes, in DMSO). The final concentration of DMSO is $0.1 \%$. In all control experiments for drugs dissolved in DMSO, $0.1 \%$ DMSO were used. BDNF (recombinant human BDNF, R\&D systems) was dissolved in phosphate-buffered saline containing $0.1 \%$ bovine serum albumin).

\section{Acknowledgments}

We thank Steven Siegelbaun, Matthew Nolan, and Sally Till for critical reading of the manuscript and helpful comments. This work was supported by the Howard Hughes Medical Institute, the New York State Psychiatric Institute, and National Institute of Mental Health Grant 5 p50-MH50733 (to E.R.K.).

\section{References}

Alarcon, J.M., Hodgman, R., Theis, M., Huang Y-S., Kandel, E.R., and Richter, J.D. 2004. Selective modulation of some forms of Schaffer collateral-CA1 synaptic plasticity in mice with a disruption of the CPEB-1 gene. Learn. Mem. 11: 318-327.

Barco, A., Alarcon, J.M, and Kandel, E.R. 2002. Expression of constitutively active CREM protein facilitates the late phase of long-term potentiation by enhancing synaptic capture. Cell 99: 221-237.

Casadio, A., Martin, K.C., Giustetto, M., Zhu, H., Chen, M., Barstch, D., Baily, C.H., and Kandel, E.R. 1999. A transient, neuron-wide form of CREB-mediated long-term facilitation can be stabilized at specific synapses by local protein synthesis. Cell 99: 221-237.

Cracco, J.B., Serano, P., Moskowitz, S.I., Bergold, P.J., and Sacktor, T.C. 2005. Protein synthesis-dependent LTP in isolated dendrites of CA1 pyramidal cells. Hippocampus 15: $1-6$.

Dudek, S. and Fields, D. 2002. Somatic action potentials are sufficient for late-phase LTP-related cell signaling. Proc. Natl. Acad. Sci. 99: 3962-3967.

Engert, F. and Bonhoeffer, T. 1999. Dendritic spine changes associated with hippocampal long-term synaptic plasticity. Nature 399: 66-70.

Fonseca, R., Nagerl, U.V., Morris, R.G.M., and Bonhoeffer, T. 2004. Competing for memory: Hippocampal LTP under regimes of reduced protein synthesis. Neuron 44: 1011-1020.

Frey, U and Morris, R.G. 1997. Synaptic tagging and long-term potentiation. Nature 385: $533-536$.

Frey, U., Krug, M., Brodemann, R., Reymann, K., and Matthies, H. 1989. Long-term potentiation induced in dendrites separated from rat's CA1 pyramidal soma does not establish a late phase. Neurosci. Lett. 97: 135-139.

Frey, U., Frey, S., Schollmeier, F., and Krug, M. 1996. A RNA synthesis inhibitor on long-term potentiation in rat hippocampal neurons in vivo and in vitro. J. Physiol. 490: 703-711.

Fukazawa, Y., Saitoh, Y., Ozawa, F., Ohta, Y., Mizuno, K., and Inokuchi, K. 2003. Hippocampal LTP is accompanied by enhanced F-actin content within the dendrites spine that is essential for late LTP maintenance in vivo. Neuron 38: 447-460.

Geinisman, Y., Detoledo, M.L., Morrell, F., Persina, I.S., and Beatty, M.A. 1996. Synapse restructuring associated with the maintenance phase of hippocampal long-term potentiation. J. Comp. Neurol.

368: 413-423.

Geoffrey, C.T., Rowe, W.B., Chow, A.R., Michael, T.H., and Rose, G.M.
2002. Theta-frequency synaptic potentiation in CA1 in vitro distinguishes cognitive impaired from unimpaired aged fischer 344 rats. J. Neurosci. 22: 9932-9940.

Golding, N.L., Staff, N.P., and Spruston, N. 2002. Dendritic spikes as a mechanism for cooperative long-term potentiation. Nature 418: $326-331$.

Impey, S., Obrietan, K., Wong, S.T., Poser, S., Yano, S., Wayman, G., Deloume, J.C., Chan, G., and Storm, D.R. 1998. Cross talk between ERK and PKA is required for $\mathrm{Ca}^{2+}$ stimulation of CREB-dependent transcription and ERK nuclear translation. Neuron 21: 869-883.

Jiang, C. and Schuman, E.M. 2002. Regulation and function of local protein synthesis in neuronal dendrites. Trends Biochem. Sci. 27: $506-515$.

Kang, H. and Schuman, E.M. 1996. A requirement for local protein synthesis in neurotrophin-induced hippocampal synaptic plasticity. Science 273: 1402-1406.

Kelleher III, R.J., Govindarajan, A., Jun, H.Y., Kang, H., and Tonegawa, S. 2004. Translation control by MAPK signaling in long term synaptic plasticity and memory. Cell 116: 467-479.

Krucker, T., Siggins, G.R., and Halpain, S. 2000. Dynamic actin filaments are required for stable long-term potentiation (LTP) in area CA1 of the hippocampus. Proc. Natl. Acad. Sci. 97: 6856-6861.

Martin, K.C. and Kosik, K.S. 2002. Synaptic tagging-who's it? Nat. Rev. Neurosci. 3: 813-820.

Martin, K.C., Casadio, A., Zhu, H., Yaping, E., Rose, J.C., Chen, M., Bailey, C.H., and Kandel, E.R. 1997. Synapse-specific, long-term facilitation of Aplysia sensory to motor synapses: A function for local protein synthesis in memory storage. Cell 91: 927-938.

Martin, K.C., Brada, M., and Kandel, E.R. 2000. Local protein synthesis and its role in synapse-specific plasticity. Curr. Opin. Neurobiol. 10: $587-592$.

Mehta, M.R. 2004. Cooperative LTP can map memory sequences on dendritic branches. Trends Neurosci. 27: 69-72.

Morozov, A., Muzzio, I.A., Bourtchouladze, R., Van-strien, N., Lapidus, K., Yin, D., Winder, D.G., Adams, J.P., Sweatt, D., and Kandel, E.R. 2003. Rap1 couples camp signaling to a distinct pool of p42/44MAPK regulating excitability, synaptic plasticity, learning, and memory. Neuron 39: 309-325.

Nayak, A., Zastrow, D.J., Lickteig, R., Zahniser, N.R., and Broming, M.D. 1998. Maintenance for late phase-LTP is accompanied by PKA-dependent increase in AMPA receptor synthesis. Nature 394: $680-683$.

Nguyen, P.V. and Kandel, E.R. 1997. Brief theta-burst stimulation induces a transcription-dependent late phase of LTP requiring cAMP in area CA1 of the mouse hippocampus. Learn. Mem. 2: 230-243.

Spruston, N., Schiller, Y., Stuart, B., and Sakman, B. 1995. Activity-dependent action potential invasion and calcium influx into hippocampal CA1 dendrites. Science 268: 297-300.

Steward, O. and Schuman, E.M. 2001. Protein synthesis at synaptic sites on dendrites. Annu. Rev. Neurosci. 24: 299-325.

Tang, S.J., Reis, G., Kang, H., Gingras, A., Sonenberg, N., and Schuman, E.M. 2002. A rapamycin-sensitive signaling pathway contributes to long-term synaptic plasticity in the hippocampus. Proc. Natl. Acad. Sci. 99: 467-472.

Thomas, M.J., Moddy, T.D., Makhinson, M., and O'Dell, T.J. 1996. Activity-dependent $\beta$-adrenergic modulation of low frequency stimulation induced LTP in the hippocampal CA1 region. Neuron 17: 475-482.

Thomas, J.M., Watabe, A.M., Moddy, T.D., Makhinson, M., and O'Dell, T.J. 1998. Postsynaptic complex spike bursting enables the induction of LTP by theta frequency synaptic stimulation. J. Neurosci. 18: $7118-7126$.

Trachtenberg, J.T., Chen, B.E., Knott, G.W., Feng, G., Sanes, J.R., Welker, E., and Svoboda, K. 2002. Long-term in vivo imaging of experience-dependent synaptic plasticity in adult cortex. Nature 420: $788-794$.

Winder, D.G., Martin, K.C., Nuzzio, I.A., Rohre, D., Chruscinski, A., Kpbilka, B., and Kandel, E.R. 1999. ERK plays a regulatory role in induction of LTP by theta frequency stimulation and its modulation by $\beta$-adrenergic receptors. Neuron 24: 715-726.

Woo, N. and Nguyen, P.V. 2003. Protein synthesis is required for synaptic immunity to depotentiation. J. Neurosci. 23: 1125-1132.

Received May 27, 2005; accepted in revised form August 23, 2005. 


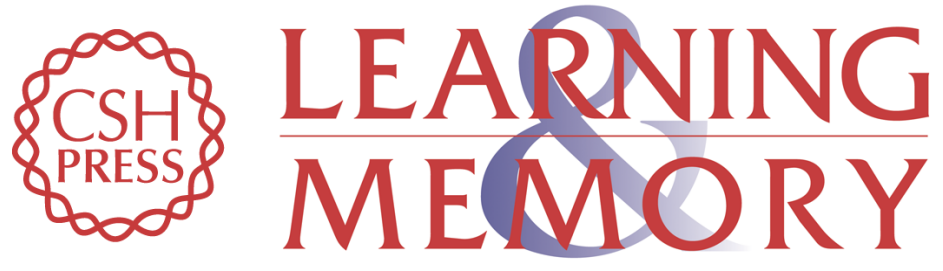

\section{Theta frequency stimulation induces a local form of late phase LTP in the CA1 region of the hippocampus}

Yan-You Huang and Eric R. Kandel

Learn. Mem. 2005, 12:

Access the most recent version at doi:10.1101/lm.98905

References This article cites 34 articles, 9 of which can be accessed free at: http://learnmem.cshlp.org/content/12/6/587.full.html\#ref-list-1

License

Email Alerting

Receive free email alerts when new articles cite this article - sign up in the box at the Service top right corner of the article or click here. 